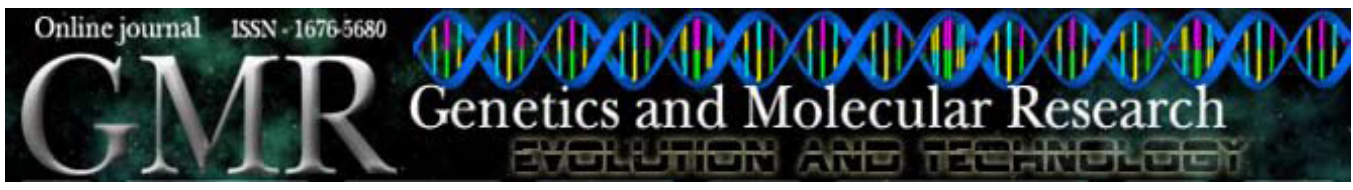

\title{
Prospecting candidate SNPs for backfat in Canchim beef cattle
}

\author{
G.B. Veneroni ${ }^{1}$, S.L. Meirelles ${ }^{1}$, D.A. Grossi ${ }^{2}$, G. Gasparin ${ }^{1}$, A.M.G. Ibelli ${ }^{1}$, \\ P.C. Tizioto ${ }^{1}$, H.N. Oliveira ${ }^{3}$, M.M. Alencar ${ }^{4}$ and L.C.A. Regitano ${ }^{4}$ \\ ${ }^{1}$ Departamento de Genética e Evolução, Universidade Federal de São Carlos, \\ São Carlos, SP, Brasil \\ ${ }^{2}$ Departamento de Ciências Exatas, \\ Universidade Estadual Paulista Júlio de Mesquita Filho, Jaboticabal, SP, Brasil \\ ${ }^{3}$ Departamento de Zootecnia, \\ Universidade Estadual Paulista Júlio de Mesquita Filho, Jaboticabal, SP, Brasil \\ ${ }^{4}$ Embrapa Pecuária Sudeste, São Carlos, SP, Brasil \\ Corresponding author: L.C.A. Regitano \\ E-mail: luciana@cppse.embrapa.br
}

Genet. Mol. Res. 9 (4): 1997-2003 (2010)

Received February 13, 2010

Accepted June 24, 2010

Published October 13, 2010

DOI 10.4238/vol9-4gmr788

\begin{abstract}
Canchim is a composite cattle breed developed in Brazil for beef production. One of the breeding objectives is to increase fat deposition. QTLs for fat thickness and/or marbling have been reported on BTA4 and BTA14. The IGFBP3 and DDEF1 genes, mapped to BTA4 and BTA14, respectively, affect adipogenesis. We looked for SNPs in the IGFBP3 and DDEF1 genes that could be associated with backfat thickness in Canchim beef cattle. For SNP identification, sires with the highest accuracy were ranked according to expected breeding value for fat thickness; the 12 extremes (six sires with the highest and six with the lowest expected breeding value for the trait) were chosen. Six regions of the IGFBP3 and 14 regions of the DDEF1 were sequenced using the Sanger method. Nine SNPs were identified in IGFBP3 and 76 in the DDEF1. After an initial analysis, two SNPs were selected to be genotyped for the whole population;
\end{abstract}


these were DDEF1g.279401A $>$ G and IGFBP3c.4394T $>C(\operatorname{Trp}>A r g)$. We found a significant effect $(\mathrm{P} \leq 0.05)$ of allele substitution on backfat thickness; however, the IGFBP3 SNP did not significantly affect this trait.

Key words: Fat deposition; Candidate genes; SNP identification; Bovine

\section{INTRODUCTION}

Bovine chromosomes 4 (BTA4) and 14 (BTA14) harbor quantitative trait loci (QTLs) for fat traits, such as marbling score and backfat thickness (Moore et al., 2003; Mizoguchi et al., 2006). Some genes, such as leptin (Stone et al., 1996) on BTA4 and thyroglobulin on BTA14 (Barendse et al., 2001), have been indicated as candidates that can influence these traits, although some of the results are conflicting (Buchanan et al., 2002; Casas et al., 2005; Rincker et al., 2006; Gan et al., 2008; Sherman et al., 2008).

The insulin-like growth factor binding protein 3 gene (IGFBP3) is located at 78.8 cM on BTA4, near a region for the marbling QTL (Mizoguchi et al., 2006). Ballard and colleagues (1988) cloned and characterized six IGFBPs in humans and rodents, which are believed to be similar to those of domestic animals. Levels of IGFBPs were related to fat mass in humans (Souren et al., 2008; Toledo-Corral et al., 2008). The development and differentiation enhancing factor 1 gene (DDEF1) is located within the region harboring QTLs for fat deposition traits on BTA14. King et al. (1999) showed that this gene has the ability to differentiate fibroblasts into adipocytes in vitro.

The objectives of this study were to identify single-nucleotide polymorphisms (SNPs) in the IGFBP3 and DDEF1 genes and to determine the association of these SNPs with fat thickness in Canchim cattle.

\section{MATERIAL AND METHODS}

\section{Animals and phenotypic data}

We evaluated 987 Canchim cattle, of both sexes (535 females and 452 bulls), raised on pasture in seven herds, all born between 2003 and 2005, for backfat thickness at the age of 18 months by image analysis using ultrasound. The images were taken and analyzed by trained technicians at the back of the lumbar region, between the 12th and 13th ribs.

\section{Animals used in identification of SNPs}

The expected breeding value (EBV) and accuracy for fat thickness were estimated for the 113 sires, parents of the 987 animals. The genetic parameters were estimated with the same data using the method of restricted maximum likelihood using the MTDFREML software (Boldman et al., 1995). The sires with the highest accuracy were ranked according to EBV, and the six sires with the highest EBV and the six with the lowest EBV were chosen for SNP 
identification in the IGFBP3 and DDEF1 genes.

\section{DNA extraction, primer design}

DNA samples were extracted using a standard salting out procedure. The sequencing primers to identify SNPs were designed using the Primer3 software (http://frodo.wi.mit. edu/primer3/) to flank the seven exons of the IGFBP3 gene and for the regions encoding the conserved domains (Centaurin Pleckstrin homology domain, ankyrin repeats, Src homology 3 domains, and ArfGap) of the DDEF1 gene. Prospecting for miRNA target sites in the miRbase (http://microrna.sanger.ac.uk/cgi-bin/targets/v5/detail_view.pl?transcript id=ENSMMinUT00000017009) revealed a sequence homologous to the target site for mmu-miR-721 miRNA in Macaca mulatta. This region was also included in the SNP prospecting experiment. We chose to target conserved domains because of the size of this gene $(339,054 \mathrm{bp})$.

\section{Identification of SNPs in the DDEF1 gene}

Six regions of the IGFBP3 gene and fourteen regions of the DDEF1 gene were amplified, purified and sequenced. The polymerase chain reaction (PCR) products were purified using the Wizard SV gel kit and PCR clean-up system (Promega ${ }^{\mathrm{TM}}$ ). Sequencing reactions were performed using the ABI PRISM ${ }^{\circledR}$ Big Dye Terminator v. 3.1 cycle sequencing kit (Applied Biosystems). The sequencing products were purified and precipitated with isopropanol and ethanol and then analyzed in an ABI Prism 3100 Avant sequencer (Applied Biosystems).

SNP identification in heterozygous individuals was performed using Phred, Phrap and Consed programs. The BioEdit program (Hall, 1999), which uses the algorithm of the ClustalW software (Thompson et al., 1994), was used to identify polymorphisms between homozygotes for different alleles of the SNP.

\section{SNP selection}

To select the SNP to be tested in the population, we determined whether the SNPs found in exons changed amino acids in proteins, and we performed the Fisher exact test to see if there was a predominance of one SNP allele in any of the fat thickness EBV extremes.

\section{SNP's genotyping in the population}

The IGFBP3c.4394T $>$ C(Trp $>$ Arg) SNP (NCBI_ss181800501) was chosen according to the analysis of amino acid change and genotyped by the TaqMan method in all families comprising more than 10 individuals (647 animals). The DDEF1 SNP chosen using the Fisher exact test (DDEF1g.279401A $>$ G, NCBI_ss181800428) was genotyped in 987 animals according to an adaptation of the ARMS methodology (Buitkamp and Semmer, 2004) and analyzed in an ABI 3100 Avant automatic DNA sequencer (Applied Biosystems). 


\section{Statistical analysis}

The associations between marker genotypes and measures of fat thickness were analyzed according to an animal model, using the restricted maximum likelihood method. In these analyses, performed using the ASREML software (Gilmour et al., 2000) according to Schenkel et al. (2005), we formed 32 contemporary groups (CG) based on the variables birth year, herd, genetic group (CA or MA), and sex. We excluded from the subsequent analysis any CGs with fewer than two individuals. To determine the influence of the molecular markers on fat thickness, we used an animal model considering as fixed effects the $\mathrm{CG}$, age of the animal (covariate, linear) and marker genotypes, besides the additive direct and the residual random effects. All analyses were performed individually for each of the two markers.

When a suggestive $(\mathrm{P} \leq 0.10)$ marker genotype effect was observed, the effect of allele substitution, such as deviation of the allele with the highest frequency, was estimated by replacing the genotype effect by covariables representing the number of copies of each allele in the genotype. A comparison between the model containing the marker genotypes and the model used in the analysis of allelic substitution effects was performed by the likelihood ratio test (Mood et al., 1974) to check for the presence of dominant deviations from the additive model.

\section{RESULTS AND DISCUSSION}

We identified nine SNPs in the IGFBP3 gene (NCBI_ss181800501 to ss181800509) of which six were located in exons (NCBI ss181800501, ss181800505, ss181800506, ss 181800507, ss 181800508 , and ss181800509) and 76 SNPs in the DDEF1 gene (NCBI ss181800425 to ss181800500), 17 of which were found in exons (NCBI_ss181800429, ss181800445, ss181800446, ss181800454, ss181800455, ss181800456, ss181800469, ss181800470, ss181800481, ss181800482, ss181800483, ss181800484, ss181800485, ss 181800491 , ss181800498, ss181800499, and ss181800500) and one in the first nucleotide of the mmu-mir-721 miRNA target site (NCBI_ss181800500). None of the IGFBP3 SNPs showed a significant effect according to the Fisher exact test; however, a $\mathrm{P}$ value of 0.0167 was revealed for the SNP (A/G) (NCBI_ss181800428) located in intron 13 of the $D D E F 1$ gene. In addition to this polymorphism, two other polymorphisms of this gene were significant $(\mathrm{P} \leq 0.05)(\mathrm{NCBI}$ ss 181800426 and ss181800486). SNPs located in the exons 4 (NCBI_ss181800501), 5 (NCBI_ss181800506) and 7 (NCBI_ss181800509) resulted in an amino acid change in IGFBP3 protein (tryptophan/arginine, cysteine/tyrosine, threonine/ methionine, respectively), changing its chemical properties (non-polar/polar or vice versa). The SNPs in exon 31 (NCBI_ss181800498, ss181800499 and ss181800500) in DDEF1 caused an amino acid alteration in DDEF1 protein (phenylalanine/leucine, valine/isoleucine and leucine/valine, respectively); however, this substitution did not affect the chemical properties of the protein structure (both were non-polar and aliphatic).

In humans, the levels of IGFBP1 showed a suggestive association with fat mass (Souren et al., 2008) and a study performed with children demonstrated that IGFBP1 and IGFBP3 are inversely related to adiposity (Toledo-Corral et al., 2008). This evidence led us to point to IGFBP3 as a candidate gene to influence fat thickness in Canchim population, but 
our hypothesis was not supported by the analysis performed (Table 1). The $\mathrm{C}$ and $\mathrm{T}$ alleles showed frequencies of 43.5 and $56.5 \%$, respectively.

Table 1. Restricted maximum likelihood analyses of backfat thickness, according to the model for each marker locus.

\begin{tabular}{|c|c|c|c|c|}
\hline \multirow[t]{3}{*}{ Effect } & \multicolumn{4}{|c|}{ SNPs } \\
\hline & \multicolumn{2}{|c|}{ DDEF1g.279401A $>\mathrm{G}$} & \multicolumn{2}{|c|}{ IGFBP3c.4394T $>C(\operatorname{Trp}>\operatorname{Arg})$} \\
\hline & d.f. & $\mathrm{P}$ & d.f. & $P$ \\
\hline Mean & 1 & $<0.01$ & 1 & 0.676 \\
\hline CG & 32 & $<0.01$ & 32 & $<0.01$ \\
\hline DDEF1g.279401A $>\mathrm{G}$ & 2 & 0.071 & - & - \\
\hline IGFBP3c.4394T $>C(\operatorname{Trp}>\mathrm{Arg})$ & - & - & 2 & 0.449 \\
\hline Age & 1 & $<0.01$ & 1 & 0.198 \\
\hline
\end{tabular}

$\mathrm{CG}=$ contemporary groups; d.f. $=$ degrees of freedom.

An indicative association $(\mathrm{P} \leq 0.07)$ was found between DDEF1g.279401A $>$ G SNP (Table 1) and backfat thickness. A QTL for fat thickness has been described in this chromosomal region (Moore et al., 2003). The protein encoded by DDEF1 gene was associated with differentiation of fibroblasts into adipocytes (King et al., 1999) and an SNP of this gene was associated with marbling in beef cattle (Casas et al., 2009).

The substitution of a $\mathrm{G}$ by an A allele in the DDEF1 marker indicated significant effects (Table 2). The A allele showed an increase in the average fat thickness of the homozygote $\mathrm{G}$ by $0.063 \mathrm{~mm}$ in the population studied (Table 2). The A and $\mathrm{G}$ alleles showed frequencies of 35.65 and $63.35 \%$, respectively. Since backfat thickness was evaluated by ultrasound, which indirectly measures carcass backfat, this could be an underestimation of the allele substitution effect.

Table 2. Results from the analysis of the effect of DDEF1g.279401A $>$ G marker allele substitution on backfat thickness of Canchim cattle and estimated regression coefficient to determine the contribution of the A allele from DDEF1g.279401A $>$ G marker in the phenotype.

\begin{tabular}{lccc}
\hline & \multicolumn{3}{c}{ DDEF1g.279401A $>$ G } \\
\hline Effect & d.f. & P & Allele effect (mm) \\
\hline Mean & 1 & $<0.01$ & - \\
CG & 32 & $<0.01$ & - \\
Alelle A & 1 & 0.027 & 0.06322 \\
Alelle G & - & - & - \\
Age & 1 & $<0.01$ & - \\
\hline
\end{tabular}

$\mathrm{CG}=$ contemporary groups; d.f. $=$ degrees of freedom; $\mathrm{P}=$ probability associated with the variance ratio test.

The model considering the genotype as fixed effect was not significantly different $(\mathrm{P}>0.05)$ from the model including the covariates for each allele for the DDEF1g.279401A $>$ G marker, and thus, the effect of this SNP on backfat could be considered strictly additive.

There are several reports of QTLs for fat deposition in both the centromeric region of BTA14 and the middle region of BTA4. However, candidate genes in these QTL regions have shown conflicting results, a fact that demonstrates the need for studies of new genes in these regions. Considering our results, the DDEF1g.279401A $>$ G SNP of the $D D E F 1$ gene could be a candidate marker for fat thickness on BTA14 in cattle to be tested in other populations. 


\section{ACKNOWLEDGMENTS}

Research supported by Embrapa, CNPq (fellowships to H.N. Oliveira, M.M. Alencar and L.C.A. Regitano) FAPESP and CAPES (scholarships to G.B. Veneroni and S.L. Meirelles) We thank the Canchim Breeding Association for support with regard to phenotypic data and DNA collection.

\section{REFERENCES}

Ballard FJ, Ross M, Upton FM and Francis GL (1988). Specific binding of insulin-like growth factors 1 and 2 to the type 1 and type 2 receptors respectively. Biochem. J. 249: 721-726.

Barendse W, Bunch R, Thomas M, Armitage S, et al. (2001). The TG5 DNA marker test for marbling capacity in Australian feedlot cattle. In: Proceedings of the Beef Quality CRC Marbling Symposium, October 9-10, Coffs Harbour, 30-35. Available at [http://www.geneticsolutions.com.au/pdf/genestar/Marbling_Bill_Barendse.pdf]. Accessed March 9, 2003.

Boldman KG, Kriese LA, Van Vleck LD, Van Tassell CP, et al. (1995). A Manual for Use of MTDFREML. A Set of Programs to Obtain Estimates of Variances and Covariances (DRAFT). Department of Agriculture, Agricultural Research Service, Lincoln.

Buchanan FC, Fitzsimmons CJ, Van Kessel AG, Thue TD, et al. (2002). Association of a missense mutation in the bovine leptin gene with carcass fat content and leptin mRNA levels. Genet. Sel. Evol. 34: 105-116.

Buitkamp J and Semmer J (2004). A robust, low- to medium-throughput prnp genotyping system in sheep. BMC Infect. Dis. 4: 30.

Casas E, White SN, Riley DG, Smith TP, et al. (2005). Assessment of single nucleotide polymorphisms in genes residing on chromosomes 14 and 29 for association with carcass composition traits in Bos indicus cattle. J. Anim. Sci. 83: 13-19.

Casas E, Wheeler TL, Shackelford SD, Bennett GL, et al. (2009). Association of Single Nucleotide Polymorphisms in Candidate Genes Residing Under Quantitative Trait Loci in Beef Cattle (abstract). Plant and Animal Genome XVII Conference, Poster No. P477, January 10-14, San Diego.

Gan QF, Zhang LP, Li JY, Hou GY, et al. (2008). Association analysis of thyroglobulin gene variants with carcass and meat quality traits in beef cattle. J. Appl. Genet. 49: 251-255.

Gilmour AR, Cullis BR, Welham SJ and Thompson DR (2000). ASREML Reference Manual. IACR-Rothamsted Experimental Station, Harpenden.

Hall TA (1999). BioEdit: a user-friendly biological sequence alignment editor and analysis program for Windows 95/98/ NT. Nucleic Acids Symp. Ser. 41: 95-98.

King FJ, Hu E, Harris DF, Sarraf P, et al. (1999). DEF-1, a novel Src SH3 binding protein that promotes adipogenesis in fibroblastic cell lines. Mol. Cell Biol. 19: 2330-2337.

Mizoguchi Y, Watanabe T, Fujinaka K, Iwamoto E, et al. (2006). Mapping of quantitative trait loci for carcass traits in a Japanese Black (Wagyu) cattle population. Anim. Genet. 37: 51-54.

Mood AM, Graybill FA and Boes DC (1974). Tests of Hypotheses. In: Introduction to the Theory of Statistics (Mood AM, Graybill FA and Boes DC, eds.). McGraw-Hill, Tokyo, 401-470.

Moore SS, Li C, Basarab J, Snelling WM, et al. (2003). Fine mapping of quantitative trait loci and assessment of positional candidate genes for backfat on bovine chromosome 14 in a commercial line of Bos taurus. J. Anim. Sci. 81: 1919-1925.

Rincker CB, Pyatt NA, Berger LL and Faulkner DB (2006). Relationship among GeneSTAR marbling marker, intramuscular fat deposition, and expected progeny differences in early weaned Simmental steers. J. Anim. Sci. 84: 686-693.

Schenkel FS, Miller SP, Ye X, Moore SS, et al. (2005). Association of single nucleotide polymorphisms in the leptin gene with carcass and meat quality traits of beef cattle. J. Anim. Sci. 83: 2009-2020.

Sherman EL, Nkrumah JD, Murdoch BM, Li C, et al. (2008). Polymorphisms and haplotypes in the bovine neuropeptide $\mathrm{Y}$, growth hormone receptor, ghrelin, insulin-like growth factor 2, and uncoupling proteins 2 and 3 genes and their associations with measures of growth, performance, feed efficiency, and carcass merit in beef cattle. J. Anim. Sci. 86: 1-16.

Souren NY, Zeegers MP, Janssen RG, Steyls A, et al. (2008). Anthropometry, carbohydrate and lipid metabolism in the East Flanders Prospective Twin Survey: linkage of candidate genes using two sib-pair based variance components analyses. Twin Res. Hum. Genet. 11: 505-516. 
Stone RT, Kappes SM and Beattie C (1996). Two polymorphic within an $18 \mathrm{~kb}$ genomic clone containing the bovine ob gene. Proceedings of the 25th International Conference on Animal Genetics. Tours, France, July 21-25 (Abstracts). Anim. Genet. 27 (Suppl 2): 64.

Thompson JD, Higgins DG and Gibson TJ (1994). CLUSTAL W: improving the sensitivity of progressive multiple sequence alignment through sequence weighting, position-specific gap penalties and weight matrix choice. Nucleic Acids Res. 22: 4673-4680.

Toledo-Corral CM, Roberts CK, Shaibi GQ, Lane CJ, et al. (2008). Insulin-like growth factor-I is inversely related to adiposity in overweight Latino children. J. Pediatr. Endocrinol. Metab. 21: 855-864. 